\title{
A Study for Analyzing the Effect of Overlapping Stenosis and Dilatation on Non-Newtonian Blood Flow in an Inclined Artery
}

\author{
Mukesh Kumar Sharma1*, Vinay Nasha1, P. R. Sharma ${ }^{2}$ \\ ${ }^{1}$ Department of Mathematics, Guru Jambheshwar University of Science \& Technology, Hisar, India \\ ${ }^{2}$ Department of Mathematics, University of Rajasthan, Jaipur, India \\ Email:^drms123@gmail.co,vinay.nasha.2@gmail.com,profprsharma@yahoo.com
}

How to cite this paper: Sharma, M.K., Nasha, V. and Sharma, P.R. (2016) A Study for Analyzing the Effect of Overlapping Stenosis and Dilatation on Non-Newtonian Blood Flow in an Inclined Artery. J. Biomedical Science and Engineering, 9, 576596.

http://dx.doi.org/10.4236/jbise.2016.912050

Received: July 20, 2016

Accepted: November 26, 2016

Published: November 29, 2016

Copyright $\odot 2016$ by authors and Scientific Research Publishing Inc. This work is licensed under the Creative Commons Attribution International License (CC BY 4.0).

http://creativecommons.org/licenses/by/4.0/

(c) (i) Open Access

\begin{abstract}
The stenosis in the artery, which reduces the flow passage to blood, is a common cardiovascular disease that is responsible even for cardiac arrest sometimes. The hemodynaics reveals that the severe blockage in an artery due to stenosis generates pressure tangential stress that impacts adversely on the arterial wall downstream to stenosis and weakens the arterial wall. The site of weakened wall in the artery generates post stenotic dilatation. The objective of this paper is to study flow of blood, of non-Newtonian in nature described by Herschel-Bulkley model, in a diseased artery suffering with partly overlapped two stenoses and a dilatation distal to the stenoses. A mathematical model, describing the blood flow, has been derived using NavierStokes equations along with the prescribed geometry of the diseased artery. The expressions of velocity profile, resistive impedance to flow and wall shear stress (skinfriction) are derived. The effect of inclination of the vessel on the resistive impedance to flow is discussed along with the effect of rheological and geometrical parameters on the resistive impedance to flow and skin friction.
\end{abstract}

\section{Keywords}

Stenotic Artery, Overlapped Stenoses, Dilatation, Herschel-Bulkley Blood, Yield Stress, Resistive Impedance

\section{Introduction}

In general, the non-Newtonian effects in blood are depending on the magnitude of deformation rates; consequently non-Newtonian effects may exist or be enhanced at low shear rates flow regimes. The types of deformation, shear or elongation also influence 
the non-Newtonian effects of blood [1]. For a given rheological model [2], the flow resistance and wall shear stress increase as the size of stenosis increases while the nonNewtonian nature of blood reduces the resistance and stress; consequently it contributes to the body protection. In this context, shear thinning seems to have the most significant role in facilitating blood flow through stenotic vessels. Under steady flow conditions blood is a predominantly shear thinning fluid that exhibits important nonNewtonian impact that was discussed by [3] [4] [5]. Blood also demonstrates yield stress which has been an issue of debates [6] [7]. A diseased artery is result of stenosis or dilatation. The word stenosis signifies the contraction of blood vessel due to deposition of fatty acids or plaque on the wall of artery. It is an abnormal and unnatural growth that develops at various locations of the cardiovascular system under diseased conditions. Through various means it is proved and well established that the constriction contributes to significant changes in the blood flow, wall shear stress, flow rate and the impedance (flow resistance) from its normal behavior. The particular cause of the occurrence of permanent dilatation is not clear. It is considered that besides complex interaction among several biological factors, some precise alterations in the hemodynamic stimuli on the arterial wall may be responsible for dilatation. After the formation of aneurysm a gradual expansion might persist on the weakened arterial wall due to the hemodynamic forces exerted by the pulsatile flow of blood. The specific alterations in the hemodynamic forces exerted on the arterial wall may play a key role to the origin and progression of the disease is widely considered hypothesis and many studies, specifically, [8]-[14] were carried out. Realizing the importance of the role of geometrical interaction with flow, several studies based on fluid dynamics through stenosed artery have been carried out to evaluate the flow pattern, wall shear stress, flow rate and impedance by many physicists and mathematicians. Newtonian blood flow in a tapered artery was studied in [15] and observed that the problem becomes more serious in the presence of an overlapping stenosis in the artery and effect of vessel tapering is another important factor. Particulate suspension blood flow through stenotic arteries, to analyze the effects of hematocrit and stenosis shape was considered in [16] and observed that the flow resistance decreases with increasing shape parameter but increases with hematocrit. Herschel-Bulkley fluid flow through an inclined tube with two mild stenoses was studied by [17] and observed that the flow resistance increases with the thickness of stenoses, yield stress and power law index. Blood flow through an overlapping constriction in arteries has been investigated by [18] and the expression for the impedance, the wall shear stress, the shear stress at the stenosis throats and at critical height of the stenosis has been derived. Shear stress at the stenosis throats and at critical height of the stenosis has been derived. Flow of blood in an inclined artery which is radially symmetric and axially non-symmetrical was discussed in [19]. The pulsatile flow through a stenosed artery filled with porous medium in the presence of transverse static magnetic field under the consideration of hematocrit dependent viscosity of blood was discussed by [20]. The pulsatile flow of blood through partially occluded elastic arteries was discussed in [21] and observed that stenosis plays a critical role in plaque growth. The 
blood flow through tapered elastic artery with overlapping stenosis was studied by [22] and computed the expressions of impedance resistance to flow and wall shear stress. Therefore, the knowledge of the flow field in a stenosed tube may help in proper understanding and curative measures of arterial diseases. This can be done through experimental as well as analytical studies. The simulations from the analytical studies may provide many outcomes in-vitro for understanding of the interconnection of hemodynamic parameters. The aim of the present study is to investigate the effects of an overlapping stenoses and a dilatation on the flow properties and hemodynamic indicators for flow of non-Newtonian blood that described by Herschel-Bulkley model.

\section{Formulation of the Problem}

It is a common clinical finding that the dilatation in the arterial wall arises distal to the constriction [23]. Also, [24] mentioned that the multiple stenoses are common in the arteries as are post-stenotic dilatations of the artery.

In the present study blood is considered as non-Newtonian in nature described by the Herschel-Bulkley model that flowing in a rigid walled unhealthy artery suffering with two stenoses which are overlapped alongside and a dilatation distal to the stenotic region. The axis of the circular tube is taken along the $\mathrm{z}$-axis and the stenoses and dilatation are assumed to be symmetrical about the z-axis. It is assumed that the tube is inclined at an angle $\alpha$ to the horizontal as shown in Figure 1. The blood vessel geometry is determined by the radius $R$ of the inlet and outlet non-constricted segment, whereas the radius of the smooth axisymmetric constricted and dilatation segment is given by

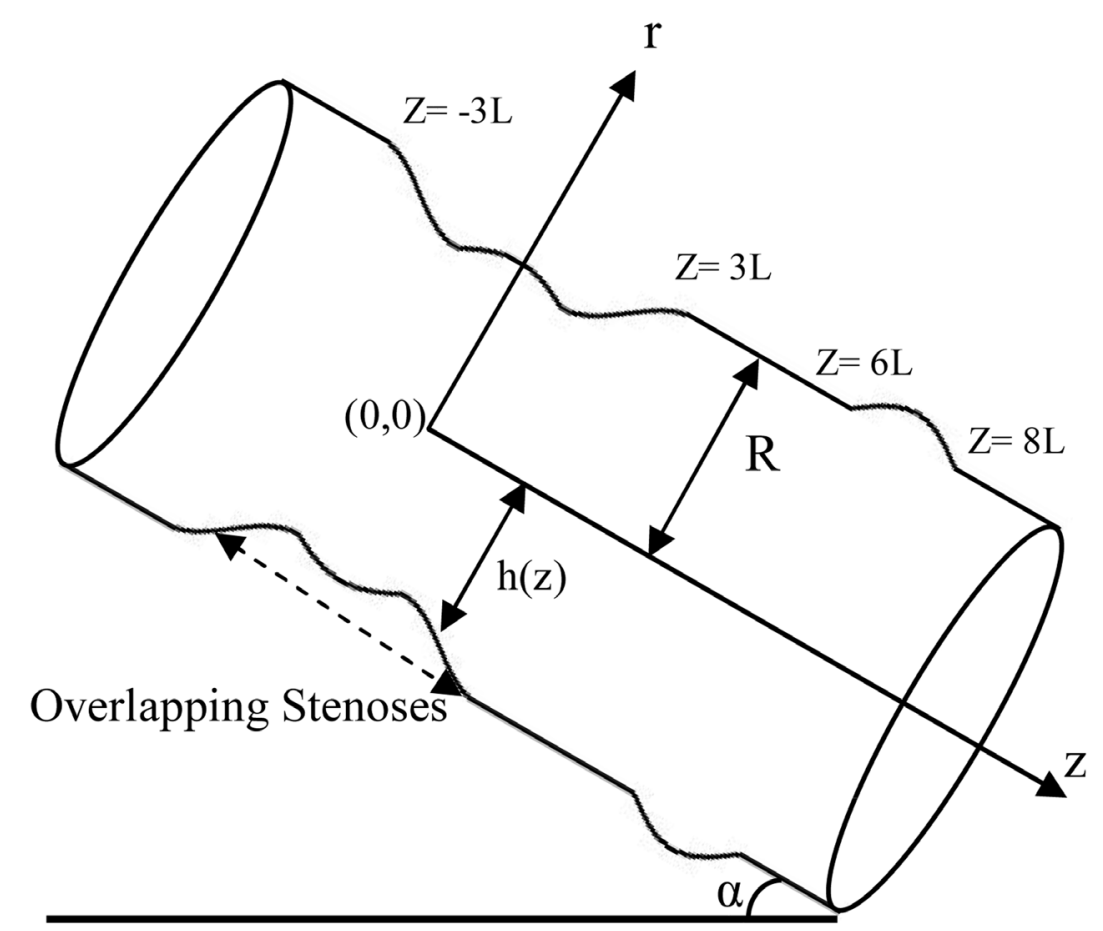

Figure 1. Physical model of the problem. 


$$
h^{*}\left(z^{*}\right)= \begin{cases}1-\frac{\delta_{1}^{*}}{2}\left(1-\sin \left(\frac{\pi z^{*}}{2 L^{*}}\right)\right) & \text { if }-3 L^{*} \leq z^{*} \leq-L^{*} \\ 1-\delta_{1}^{*}\left(1-\frac{1}{4} \cos \left(\frac{\pi z^{*}}{2 L^{*}}\right)\right) & \text { if }-L^{*} \leq z^{*} \leq L^{*} \\ 1-\frac{\delta_{1}^{*}}{2}\left(1+\sin \left(\frac{\pi z^{*}}{2 L^{*}}\right)\right) & \text { if } L^{*} \leq z^{*} \leq 3 L^{*} \\ 1+\delta_{2}^{*} \sin \left(\frac{\pi z^{*}}{2 L^{*}}\right) & \text { if } 6 L^{*} \leq z^{*} \leq 8 L^{*} \\ 1 & \text { otherwise }\end{cases}
$$

where, $6 L$ is the length of stenosed segment and $2 L$ is the length of dilatation segment. The $\delta_{1}$ is maximum thickness of the stenosis and $\delta_{2}$ is maximum dilatation in the arterial wall. In the axisymmetric coordinates system $\left(r^{*}, \theta^{*}, z^{*}\right)$, the axis of the vessel is coincides with the $Z^{*}$-axis.

The function $h(z)$ is plotted on MatLab to draw the Figure 1 .

The equation of continuity for incompressible fluid is given by

$$
\frac{1}{r^{*}} \frac{\partial\left(r^{*} u^{*}\right)}{\partial r^{*}}+\frac{\partial w^{*}}{\partial z^{*}}=0
$$

Since, flow is axisymmetric, i.e., $\frac{\partial(.)}{\partial \theta^{*}}=0$, and there is no radial flow, i.e., $v^{*}=0$. Also, flow is developed, i.e., $\frac{\partial w^{*}}{\partial z^{*}}=0$.

The governing equation of motion for steady developed flow of blood in the inclined vessel is given by

$$
0=-\frac{\partial p^{*}}{\partial z^{*}}-\mu\left(\frac{1}{r^{*}} \frac{\partial}{\partial r^{*}}\left(r^{*} \tau_{r z}^{*}\right)\right)+\rho g \sin \alpha
$$

where, $g$ is acceleration due to gravity and $\tau_{r z}^{*}$ is shear stress.

The Herschel-Bulkley fluid is defined by the constitutive equation

$$
\begin{gathered}
-\frac{\partial w^{*}}{\partial r^{*}}=f\left(\tau_{r z}^{*}\right)=\frac{1}{k}\left(\tau_{r z}^{*}-\tau_{0}^{*}\right)^{n}, \quad \tau_{r z}^{*}>\tau_{0}^{*} \\
\frac{\partial w^{*}}{\partial r^{*}}=0, \quad \tau_{r z}^{*}<\tau_{0}^{*}
\end{gathered}
$$

where, $\tau_{0}^{*}$ is yield stress, $n$ and $k$ are parameters which represents non-Newtonian effects.

The boundary conditions are given by

$$
\begin{aligned}
& r^{*}=0: \tau_{r z}^{*} \text { is finite } \\
& r^{*}=h^{*}\left(z^{*}\right): w^{*}=0 .
\end{aligned}
$$

\section{Method of Solution}

Using the following non-dimensional parameters: 
$r=\frac{r^{*}}{R}, \quad z=\frac{z^{*}}{R}, \quad h=\frac{h^{*}}{R}, \quad L=\frac{L^{*}}{R}, \quad \delta_{1}=\frac{\delta_{1}^{*}}{R} \quad \delta_{2}=\frac{\delta_{2}^{*}}{R}, \quad \rho g=\frac{q_{0}}{F}, \quad \frac{\partial p^{*}}{\partial z^{*}}=q_{0} \frac{\partial p}{\partial z}$, $u=\frac{u^{*}}{\left(\frac{q_{0} R^{2}}{2 \mu}\right)} w=\frac{w^{*}}{\left(\frac{q_{0} R^{2}}{2 \mu}\right)}, \tau_{r z}=\frac{\tau_{r z}^{*}}{\left(\frac{q_{0} R}{\mu}\right)}$, into the Equations (1) to (7), the non-dimensional form of these equations are given by (8) to (14), respectively

$$
h(z)=\left\{\begin{array}{cc}
1-\frac{\delta_{1}}{2}\left(1-\sin \left(\frac{\pi z}{2 L}\right)\right) & \text { if }-3 L \leq z \leq-L \\
1-\delta_{1}\left(1-\frac{1}{4} \cos \left(\frac{\pi z}{2 L}\right)\right) & \text { if }-L \leq z \leq L \\
1-\frac{\delta_{1}}{2}\left(1+\sin \left(\frac{\pi z}{2 L}\right)\right) & \text { if } L \leq z \leq 3 L \\
1+\delta_{2} \sin \left(\frac{\pi z}{2 L}\right) & \text { if } 6 L \leq z \leq 8 L \\
1 \quad & \text { otherwise } \\
\frac{1}{r} \frac{\partial(r u)}{\partial r}+\frac{\partial w}{\partial z}=0 .
\end{array}\right.
$$

The equation of motion is

$$
-\frac{\partial p}{\partial z}+\frac{\sin \alpha}{F}=\frac{1}{r} \frac{\partial}{\partial r}\left(r \tau_{r z}\right)
$$

where, $\tau_{r z}$ is dimensionless shear stress for Herschel-Bulkley fluid and given by:

$$
\begin{gathered}
-\frac{\partial w}{\partial r}=f\left(\tau_{r z}\right)=\frac{1}{k}\left(\tau_{r z}-\tau_{0}\right)^{n}, \quad \tau_{r z}>\tau_{0} \\
\frac{\partial w}{\partial r}=0, \quad \tau_{r z}<\tau_{0} .
\end{gathered}
$$

Corresponding boundary conditions are reduced to

$$
\begin{aligned}
& r=0: \tau_{r z} \text { is finite } \\
& r=h(z): w=0 .
\end{aligned}
$$

Equation (10) can be written as

$$
\frac{\partial}{\partial r}\left(r \tau_{r z}\right)=r\left(-\frac{\partial p}{\partial z}+f\right)
$$

where, $f=\frac{\sin \alpha}{F}$.

The solution of (15) under the boundary condition (13) gives

$$
\tau_{r z}=\frac{r}{2}\left(-\frac{\partial p}{\partial z}+f\right)
$$

Using (16) in the constitutive Equation (11) for $\tau_{r z}>\tau_{0}$ provides

$$
\left(-k \frac{\partial w}{\partial r}\right)^{1 / n}=\left(-\frac{\partial p}{\partial z}+f\right) \frac{r}{2}-\tau_{0}
$$




$$
\frac{\partial w}{\partial r}=-\frac{1}{k}\left(\left(-\frac{\partial p}{\partial z}+f\right) \frac{r}{2}-\tau_{0}\right)^{n}
$$

Integrating Equation (17) w.r.t. $r$ and applying boundary condition (14), the $w(r)$ is given by

$$
w(r)=-\frac{\left(-\frac{\partial p}{\partial z}+f\right)^{n}}{2 k(n+1)}\left(\left(1-\frac{2 \tau_{0}}{\left(-\frac{\partial p}{\partial z}+f\right)}\right)^{n+1}-\left(r-\frac{2 \tau_{0}}{\left(-\frac{\partial p}{\partial z}+f\right)}\right)^{n+1}\right)
$$

\subsection{Skin Friction $\left(\tau_{h(z)}\right)$}

The skin friction $\tau_{h(z)}$ from Equation (16) is given by

$$
\tau_{h}=\frac{h(z)}{2}\left(-\frac{\partial p}{\partial z}+f\right) \text {. }
$$

\subsection{Volumetric Flow Rate $(Q)$}

$$
Q=\frac{\pi h^{3}(z)}{\tau_{h}^{3}} \int_{0}^{\tau_{h}} \tau^{2} f(\tau) \mathrm{d} \tau
$$

Substituting the value of $f(\tau)$ from Equations (11) into (20), we obtain

$$
\begin{aligned}
Q & =\frac{\pi h^{3}(z)}{\tau_{h}^{3}} \int_{0}^{\tau_{h}} \frac{\tau^{2}}{k}\left(\tau-\tau_{0}\right)^{n} \mathrm{~d} \tau \\
& =\frac{\pi h^{3}(z) \tau_{h}^{n}}{k(n+3)}\left(1-\frac{\tau_{0}}{\tau_{h}}\right)^{n+1}\left(1+\frac{2}{n+2}\left(\frac{\tau_{0}}{\tau_{h}}\right)+\frac{2}{(n+1)(n+2)}\left(\frac{\tau_{0}}{\tau_{h}}\right)^{2}\right)
\end{aligned}
$$

when $\frac{\tau_{0}}{\tau_{h}} \ll 1$, then Equation (21) reduces to

$$
Q=\frac{\pi h^{3}(z)}{k(n+3)}\left(\tau_{h}-\left(\frac{n+3}{n+2}\right) \tau_{0}\right)^{n} .
$$

From the Equation (22), $\tau_{h}$ is given by

$$
\tau_{h}=\left(\frac{Q k(n+3)}{\pi h^{3}(z)}\right)^{1 / n}+\left(\frac{n+3}{n+2}\right) \tau_{0} .
$$

Using Equation (19) in Equation (23)

$$
-\frac{\partial p}{\partial z}=\left(\left(\frac{2^{n} Q k(n+3)}{\pi h^{n+3}(z)}\right)^{1 / n}+\frac{2}{h(z)}\left(\frac{n+3}{n+2}\right) \tau_{0}-f\right) .
$$

\subsection{Pressure Drop $(\Delta p)$}

The pressure drop $\Delta p$ across the stenosis can be obtained by integrating the Equation (24) along the length of the artery from $-5 \mathrm{~L}$ to $10 \mathrm{~L}$, 


$$
\begin{aligned}
\Delta p & =\int_{-5 L}^{10 L}\left(-\frac{\partial p}{\partial z}\right) \mathrm{d} z \\
& =\int_{-5 L}^{10 L}\left(\left(\frac{2^{n} Q k(n+3)}{\pi h^{n+3}(z)}\right)^{1 / n}+\frac{2}{h(z)}\left(\frac{n+3}{n+2}\right) \tau_{0}-f\right) \mathrm{d} z .
\end{aligned}
$$

In the absence of any constriction, the pressure drop $\Delta p_{N}$ is given by

$$
\Delta p_{N}=\int_{-5 L}^{10 L}\left(\left(\frac{2^{n} Q k(n+3)}{\pi}\right)^{1 / n}+2\left(\frac{n+3}{n+2}\right) \tau_{0}-f\right) \mathrm{d} z .
$$

\subsection{Impedance (Resistance to Flow Ratio $\lambda$ )}

The resistance to flow $\left(\lambda_{1}\right)$ in the diseased artery is given by

$$
\begin{aligned}
\lambda_{1} & =\frac{\text { pressure drop }(\Delta p)}{\text { Volumetric flow rate }(Q)} \\
& =\frac{1}{Q} \int_{-5 L}^{10 L}\left(\left(\frac{2^{n} Q k(n+3)}{\pi h^{n+3}(z)}\right)^{1 / n}+\frac{2}{h(z)}\left(\frac{n+3}{n+2}\right) \tau_{0}-f\right) \mathrm{d} z .
\end{aligned}
$$

If there is no diseased portion then resistance to flow is given by

$$
\lambda_{N}=\frac{1}{Q} \int_{-5 L}^{10 L}\left(\left(\frac{2^{n} Q k(n+3)}{\pi}\right)^{1 / n}+2\left(\frac{n+3}{n+2}\right) \tau_{0}-f\right) \mathrm{d} z .
$$

Therefore, the impedance-resistance to flow ratio may be expressed as

$$
\lambda=\frac{\lambda_{1}}{\lambda_{N}}
$$

From Equation (27) and (28), $\lambda$ is expressed as

$$
\lambda=\frac{\int_{-5 L}^{10 L}\left(\left(\frac{2^{n} Q k(n+3)}{\pi h^{n+3}(z)}\right)^{1 / n}+\frac{2}{h(z)}\left(\frac{n+3}{n+2}\right) \tau_{0}-f\right) \mathrm{d} z}{\int_{-5 L}^{10 L}\left(\left(\frac{2^{n} Q k(n+3)}{\pi}\right)^{1 / n}+2\left(\frac{n+3}{n+2}\right) \tau_{0}-f\right) \mathrm{d} z} .
$$

The values of $\lambda$ are computed numerically using Simpson's one-third rule and presented through graphs.

\section{Results and Discussion}

The effects of various parameters pertinent to the model on velocity profile, skin-friction and impedance are computed and plotted to analyze them.

Figure 2 demonstrates the effect of varying thickness of the overlapped stenosed segment keeping other parameters fixed. It is observed that the axial flow velocity enhances with the increase in the thickness of the stenosis. As per mathematical formulation of the geometry, it can be seen that in the overlapped portion of the stenoses 


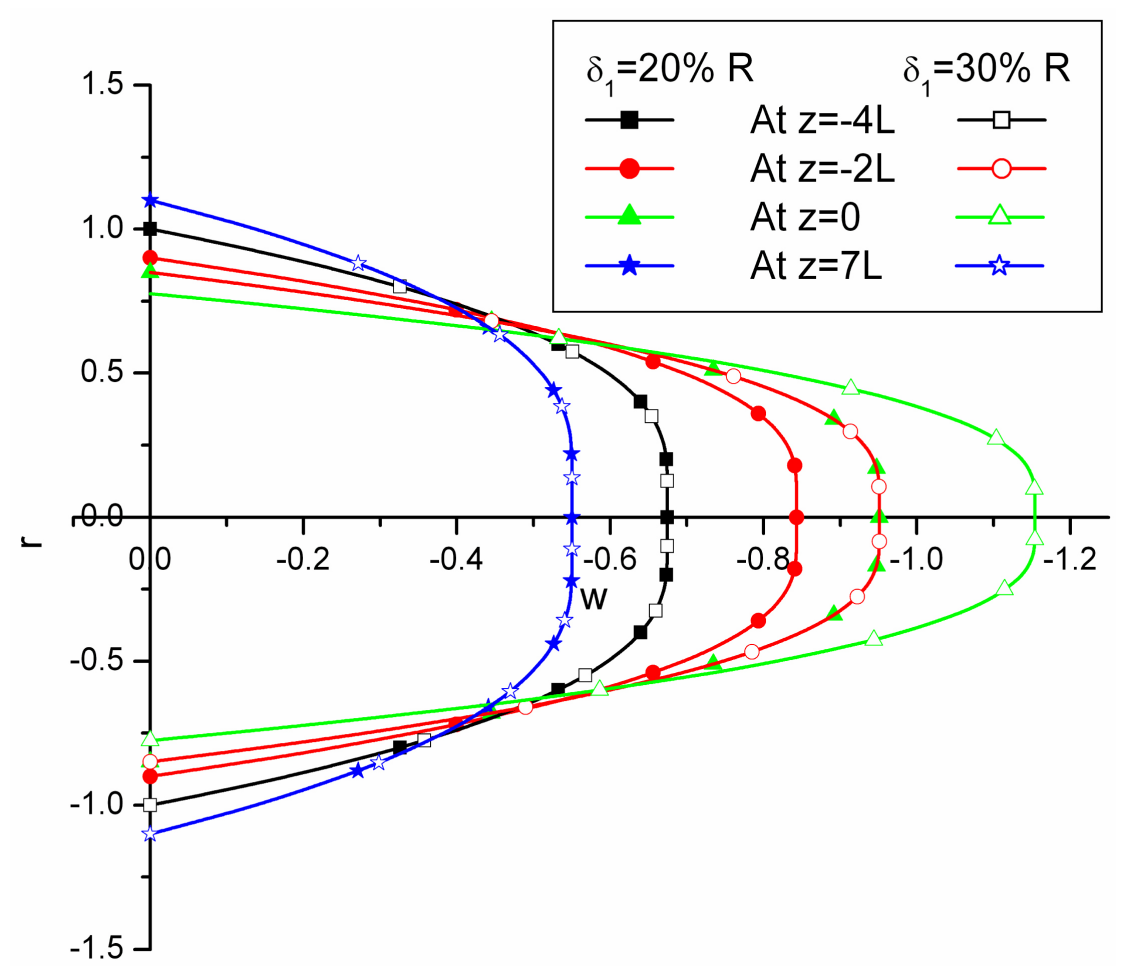

Figure 2. Variation in velocity profile in radial direction at $k=4, n=1.5, \alpha=\pi / 6, \tau_{0}=$ $0.5, \delta_{2}=10 \%$ of $R$.

having peak at the location $z=-2 L$ corresponding to which $h(z)=\frac{18}{20}$ and at $z=0, h(z)=\frac{17}{20}$, therefore the projection of stenosis in the lumen at $z=0$ is more as compared to that at $z=-2 L$. It is observed that flow velocity at $z=0$ is more as compared to that at $z=-2 L$. Also, in the dilatation region the effect of $\delta_{1}$ is not observed. The plug flow radius decreases significantly with the increase of maximum thickness of stenosis.

Figure 3 demonstrates the effect of varying thickness of dilatation at different locations starting from the pre constricted region i.e. at location $Z=-4 L$. It is observed that the axial velocity at the locations in the stenosed region located at $z=-2 L$ and $z=0$, the respective passage is $h(-2 L)=\frac{18}{20}$ and $h(0)=\frac{17}{20}$, the flow velocity significantly increases with the reduction of the flow passage. It is plausible that the flow velocity reduces from the velocity in the normal region of the vessel. In the dilatation region, the flow velocity reduces significantly in magnitude as compared to the other locations in the region of overlapped stenosis or normal region of vessel.

The flow velocity retarded with the increase in the maximum dilatation in the vessel wall. The results in the region of stenosis and effect of maximum thickness of stenosis on the flow profile pattern are in good agreement with results already published. The effect of non-Newtonian behaviour of blood as compare to blood of Newtonian nature is plausible as the profiles are not of parabolic shape. 


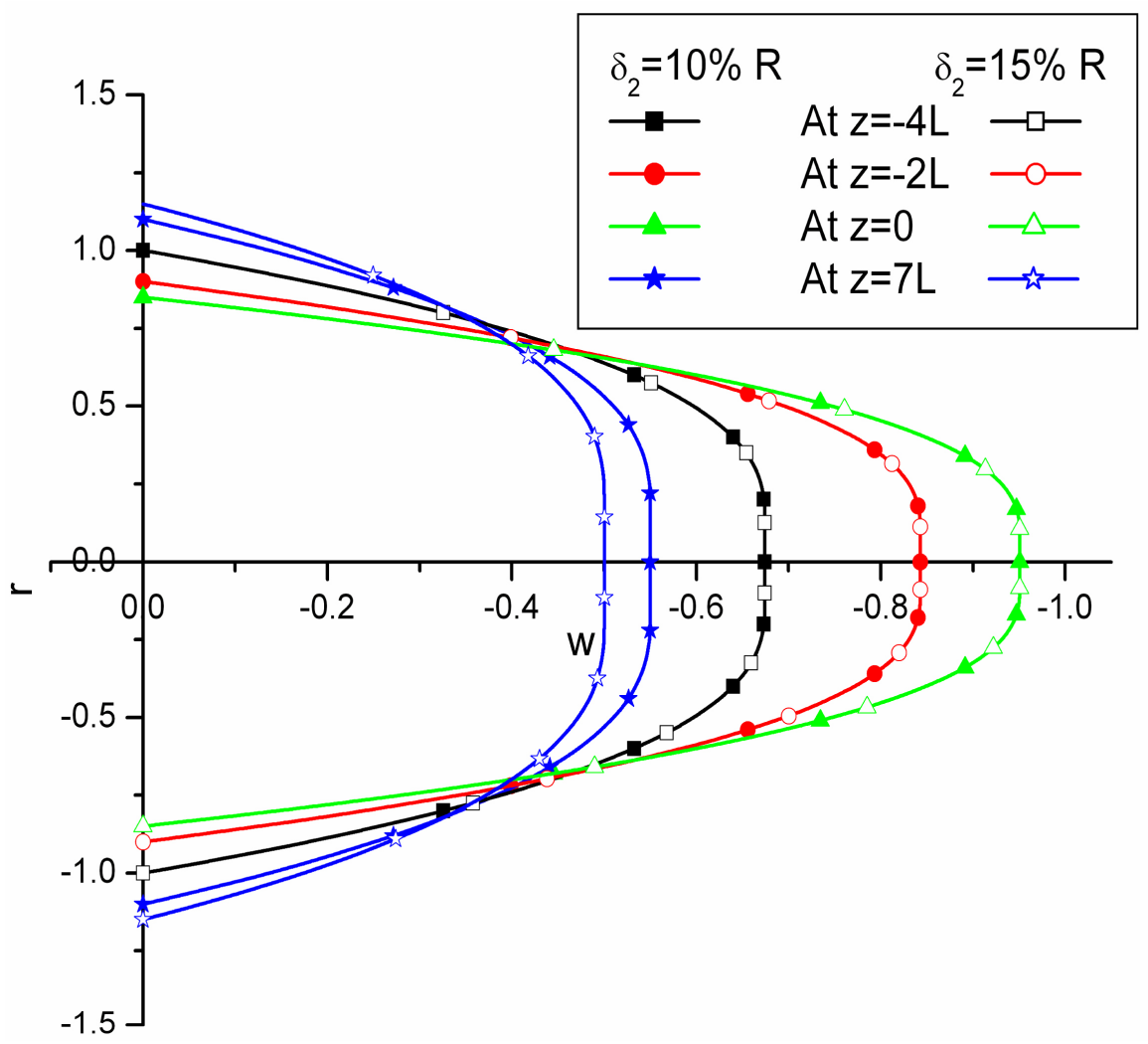

Figure 3. Variation in velocity profile in radial direction at $k=4, n=1.5, \alpha=\pi / 6, \tau_{0}=0.5$, $\delta_{1}=20 \%$ of $R$.

In the healthy human blood, the value of yield stress ranges in between $0.01 \mathrm{dyne} / \mathrm{s}^{2}$ and $0.06 \mathrm{dyne} / \mathrm{s}^{2}$, while in unhealthy human, suffering with myocardial infarction the yield stress may increases up to five times [25].

The measurement of yield stresses may used in the diagnosis of pathological conditions such as diabetes [26], systemic sclerosis [27] etc. With pressure-scanning capillary hemorheometer [28] the yield stress for the Herschel-Bulkley model was found 0.0325 dyne $/ \mathrm{s}^{2}$. In the present study the values of yield stress are taken $0.05,0.025$ and 0.50 . The last value correlates the diseased situation.

Figure 4 shows comparative study for velocity profile in respect of yield stress of healthy and diseased arterial blood. In unhealthy situation at the yield stress $\tau_{0}=0.5$, the plug flow radius increases irrespective of the locations whether it is falls within region of the stenosis or in the region of dilatation.

Figure 5 depict the effect of power law index on the flow profiles. It is observed that velocity profiles enhances in all region of the vessel. This enhancement in the profiles is more in the region having lesser flow passage. The plug flow radius become widen with the increase of power law index. The flow profiles at greater value of power law index are tends to be curved in the vicinity of the axial line while for small value of power law index profiles are flatten. This shows that with increasing power law index the fluid get impetus even in the plug flow region. 


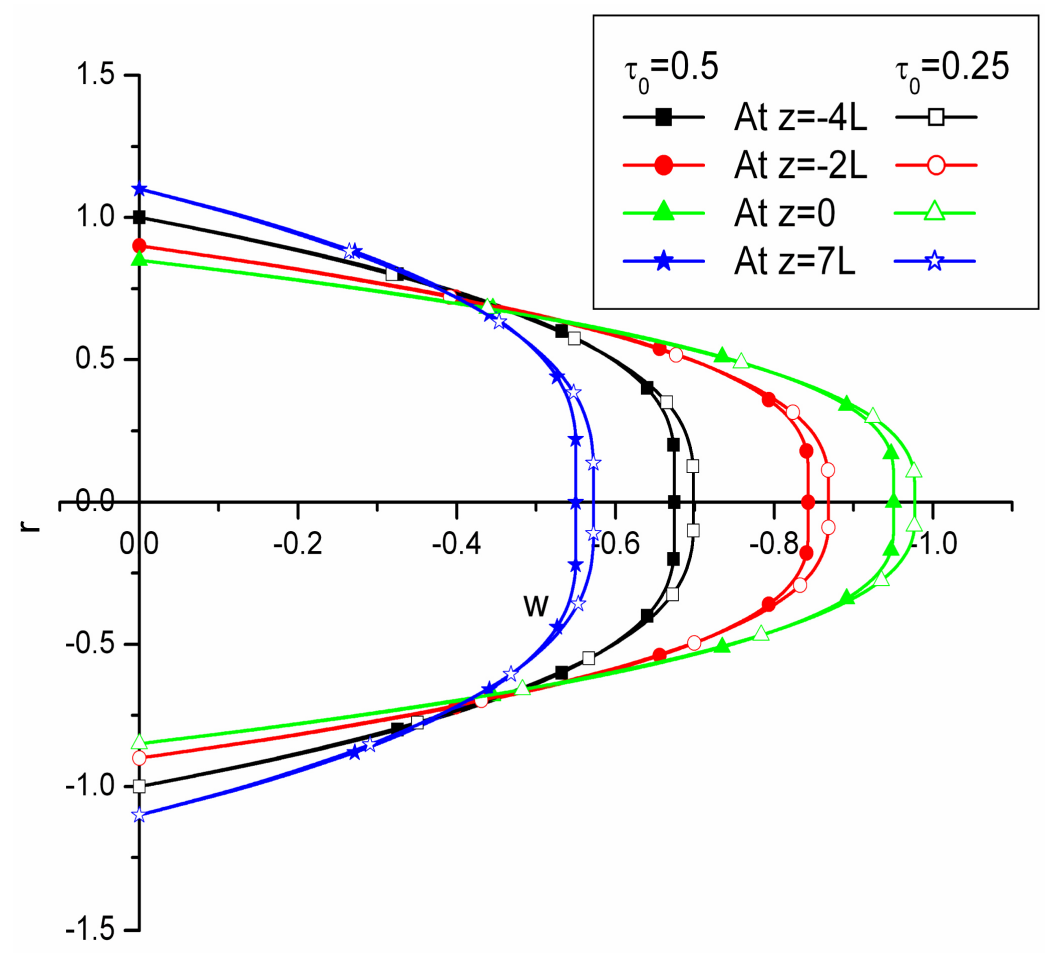

Figure 4. Variation in velocity profile in radial direction at $k=4, n=1.5, \alpha=\pi / 6$, $\delta_{1}=10 \%, \delta_{2}=10 \%$ of $R$.

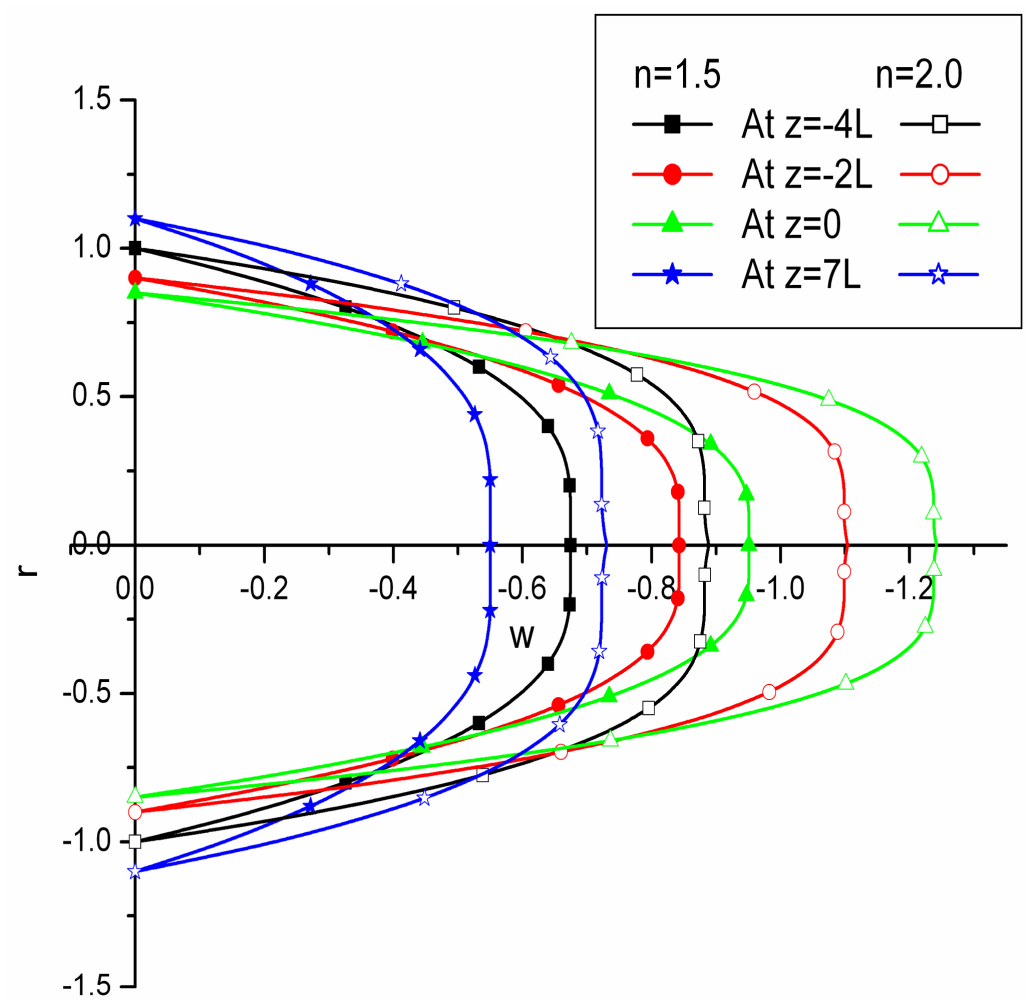

Figure 5. Variation in velocity profile in radial direction at $k=4, n=1.5, \alpha=\pi / 6$, $\tau_{0}=0.5, \delta_{1}=20 \%$ of $R, \delta_{2}=10 \%$ of $R$. 
Figure 6 shows the effect of degree of stenosis on the skin-friction along the axial direction. The skin-friction is more for lower value of maximum thickness of overlapped stenoses. Also, the skin-friction sharply increases in the region of growing thickness of stenosis up to apex of maximum thickness and reduces in the overlapped stenotic region and then again rises up to second peak of the overlapped region.

Figure 7 depict that in the region of dilatation, the skin-friction reduces with the increase of maximum expansion of dilatation in the artery. This reduction in the skinfriction with the increase in expansion of dilatation is lesser than the rise in the stenotic region.

Figure 8 demonstrates the effect of yield stress on the skin-friction. With the increase in the value of yield stress, there is significant increase in the skin-friction in the entire region. Near the extremities of the overlapped stenosis, the steepest enhancement in the skin-friction is observed. This outcome suggests that in case of unhealthy situation at the yield stress $\tau_{0}=0.5$ arterial wall bears more stresses which may responsible for the wall rupturing.

The typical values of the power index $\mathrm{n}$ for blood flow is taken to lie between 0.9 and 1.1 are used in [29].

Figure 9 depicts the effect of power law index on the skin-friction. With the increase in power law index profound reduction in skin-friction is obtained. This proves the importance of power law index of the blood during the theoretical studies. The increase

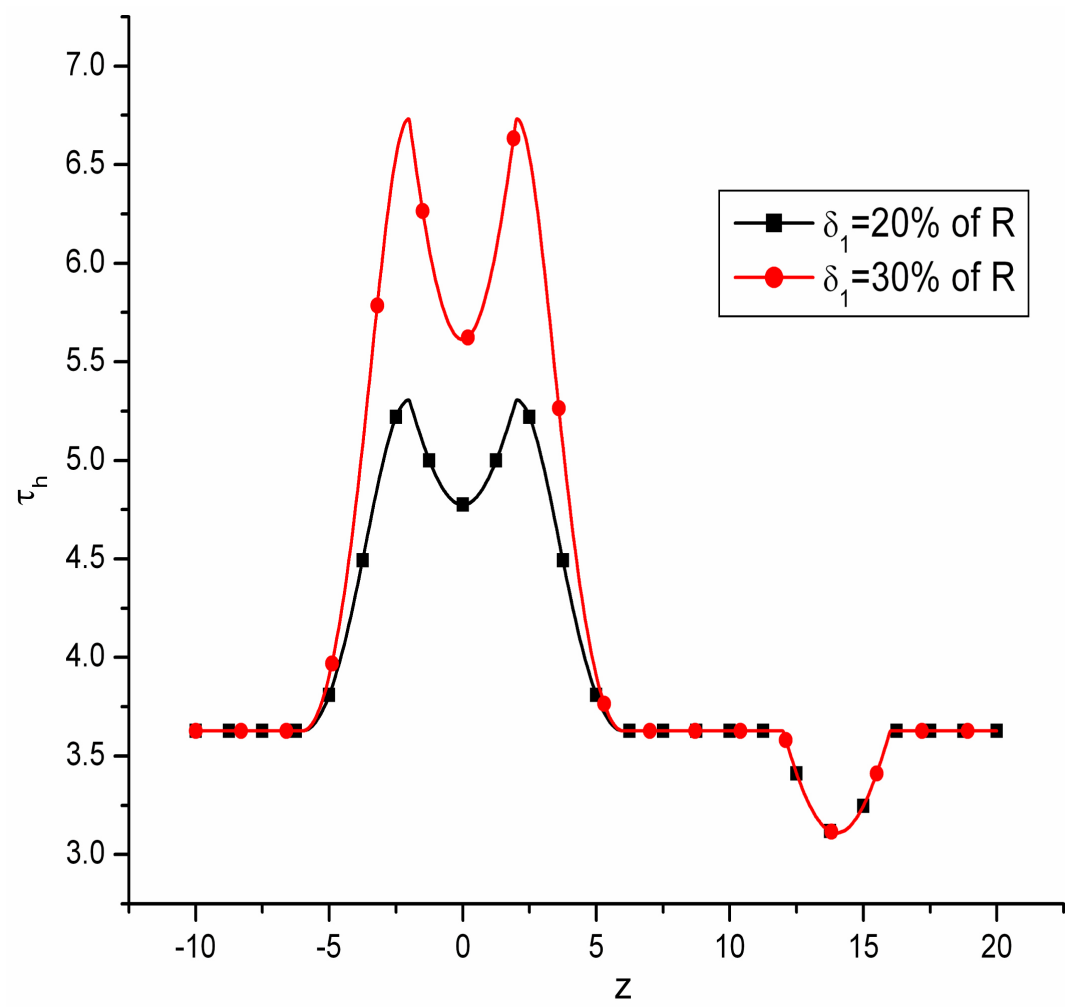

Figure 6. Variation in skin-friction in axial direction at $k=4, n=1.5, \alpha=\pi / 6, \tau_{0}=$ $0.5, \delta_{2}=10 \%$ of $R$. 


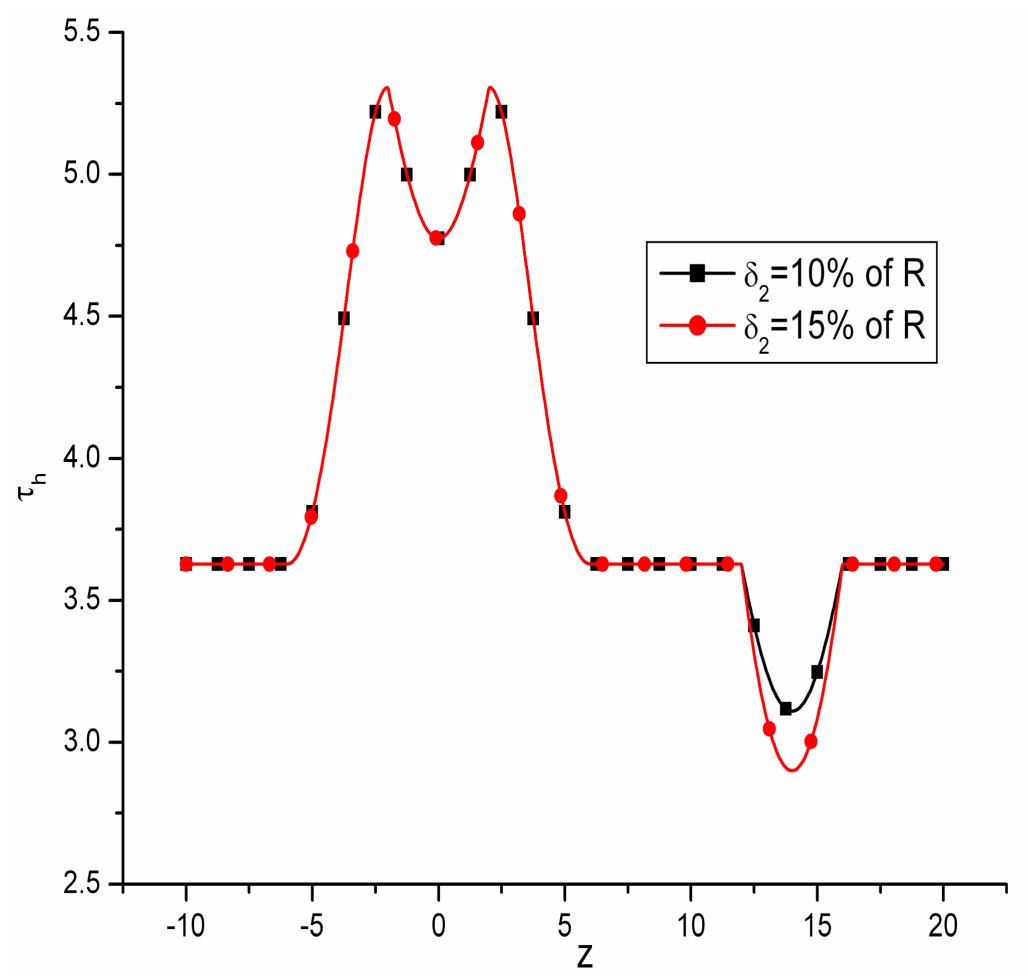

Figure 7. Variation in skin-friction in axial direction at $k=4, n=1.5, \alpha=\pi / 6$, $\tau_{0}=0.5, \delta_{1}=20 \%$ of $R$.

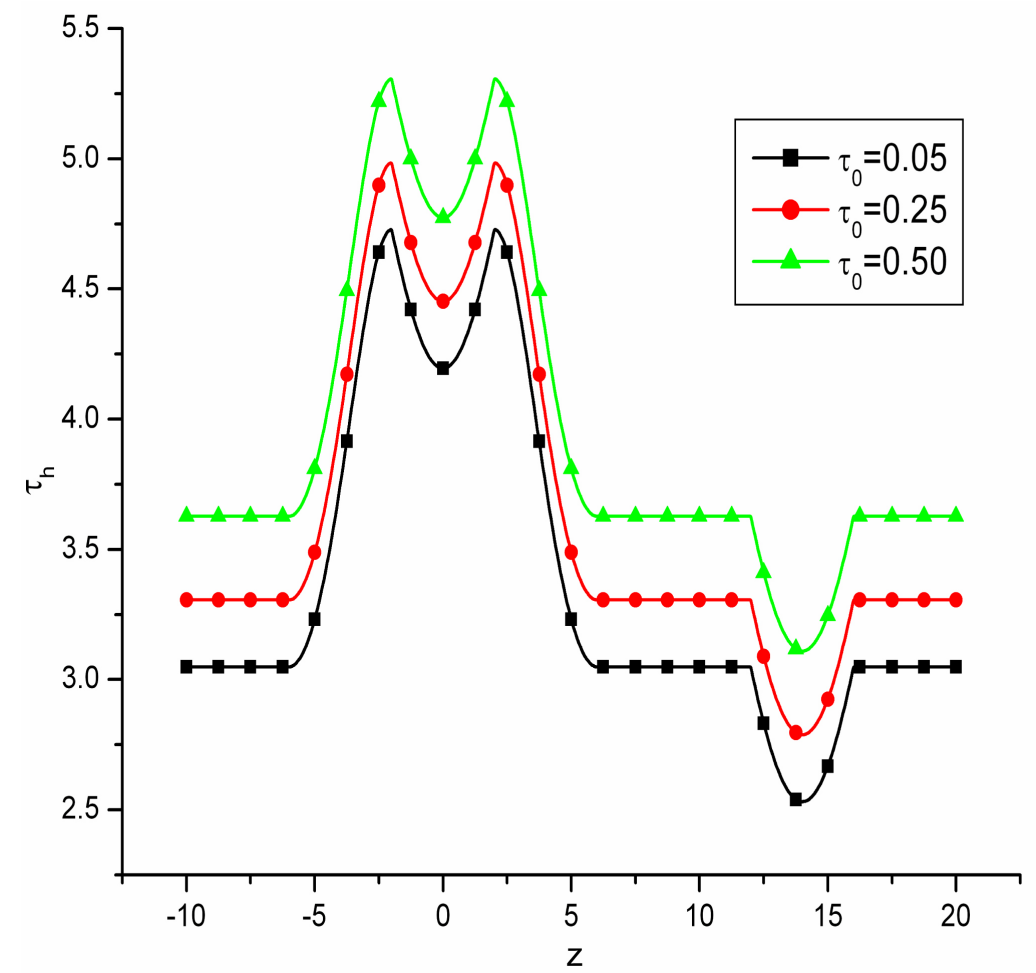

Figure 8. Variation in skin-friction in axial direction at $k=4, n=1.5, \alpha=\pi / 6$, $\delta_{1}=20 \%$ of $R, \delta_{2}=10 \%$ of $R$. 


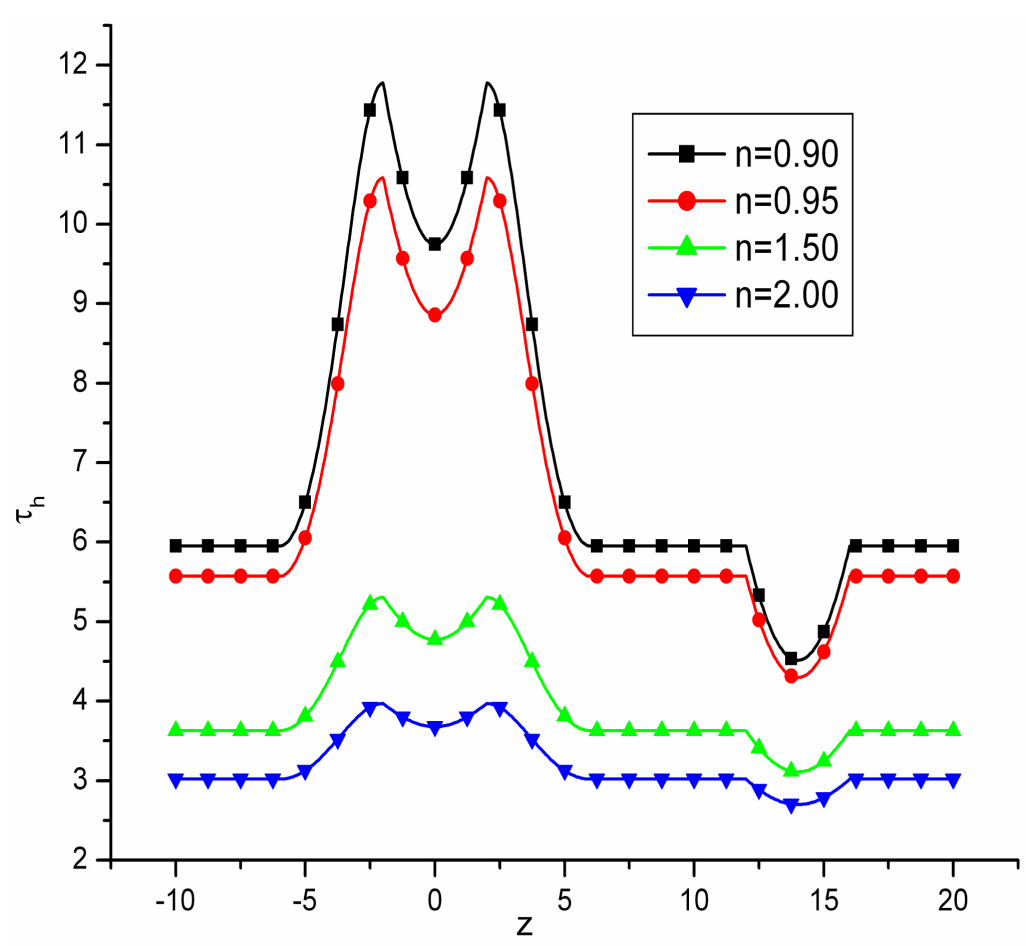

Figure 9. Variation in skin-friction in axial direction at $k=4, \tau_{0}=0.5, \alpha=\pi / 6$, $\delta_{1}=20 \%$ of $R, \delta_{2}=10 \%$ of $R$.

in power law index overcomes the stress on wall of the vessel consequently on the endothelial cells.

Corresponding to a fixed thickness of stenosis, the increase in maximum expansion in dilatation of the vessel, the impedance to the flow is reduces as observed in Figure 10. Also, it is plausible from Figure 10 that for a fixed value of maximum expansion in the dilatation, the impedance to the flow rises on increasing maximum thickness of the pre stenotic region. Findings of this study are in good agreement with outcomes of [30].

Figure 11 \& Figure 12 show that the increase in yield stresses increases impedance to the flow. This suggests that in case of unhealthy situation, at the yield stress $\tau_{0}=0.5$, the resistance to flow ratio increases hence the reduction in the transportation of blood, results in the less oxygen and nutrients supply to the tissues. It is also evident from the Figure 11 that when projection of stenosis increases in the lumen the impedance increases while from Figure 12 it is seen that when the expansion of the dilatation increases the impedance decreases.

Figure 13 shows that corresponding to a fixed expansion in dilatation; the increase in maximum thickness of stenotic region has enhanced impedance to the flow. Also, it is plausible from Figure 13 that for a fixed value of maximum thickness of the stenotic region, the impedance to the flow lowered down on increasing maximum expansion of the dilatation.

The impedance to the flow reduces with the increase of power law index as shown in Figure 14 \& Figure 15. It is noted that in both the cases of $n<1$ or $n>1$ impedance 


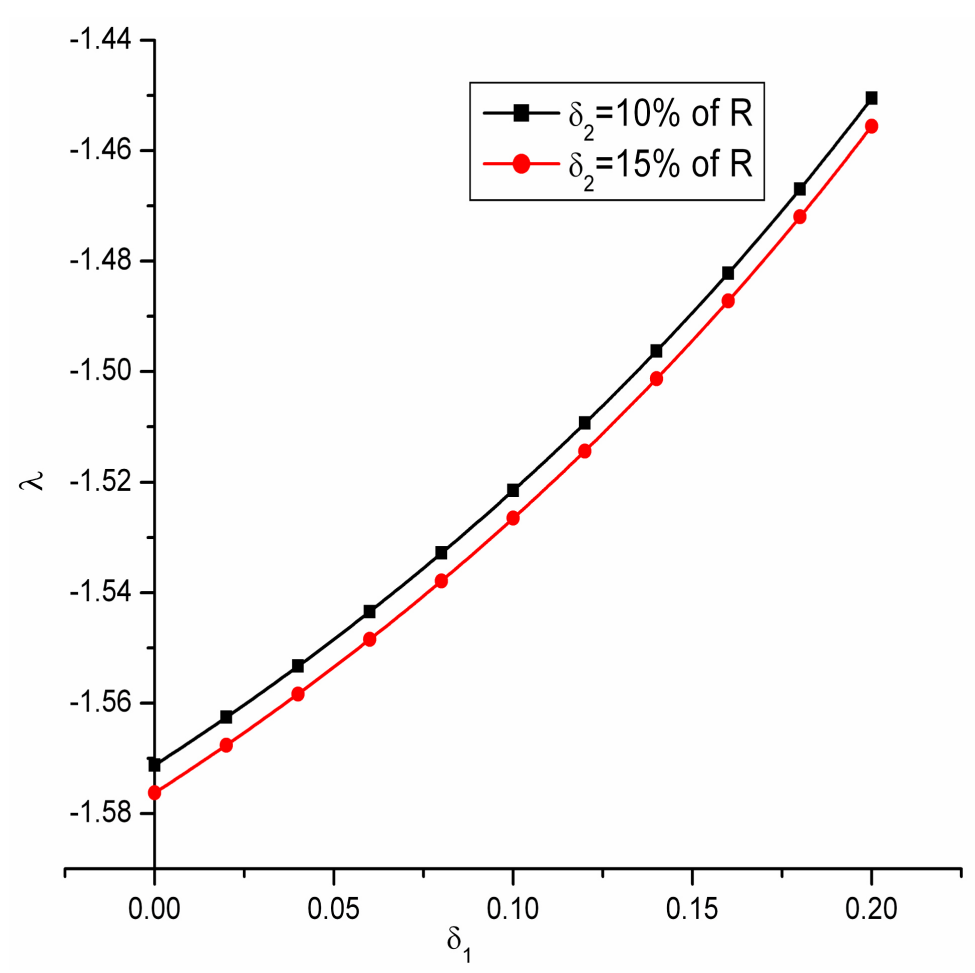

Figure 10. Variation in impedance with thickness of stenosis at $k=4, n=$ $1.5, \alpha=\pi / 6, \tau_{0}=0.5$.

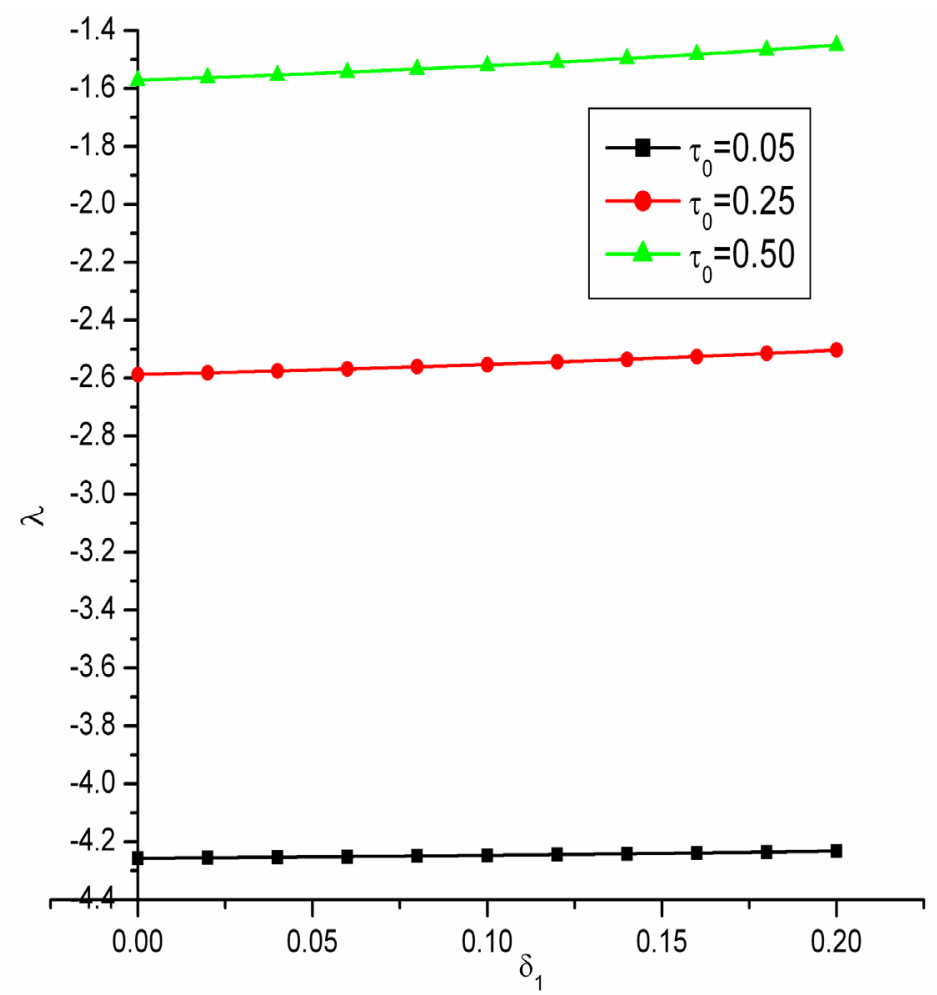

Figure 11. Variation in impedance with thickness of stenosis at $k=4, n=$ $1.5, \alpha=\pi / 6, \delta_{2}=10 \%$ of $R$. 


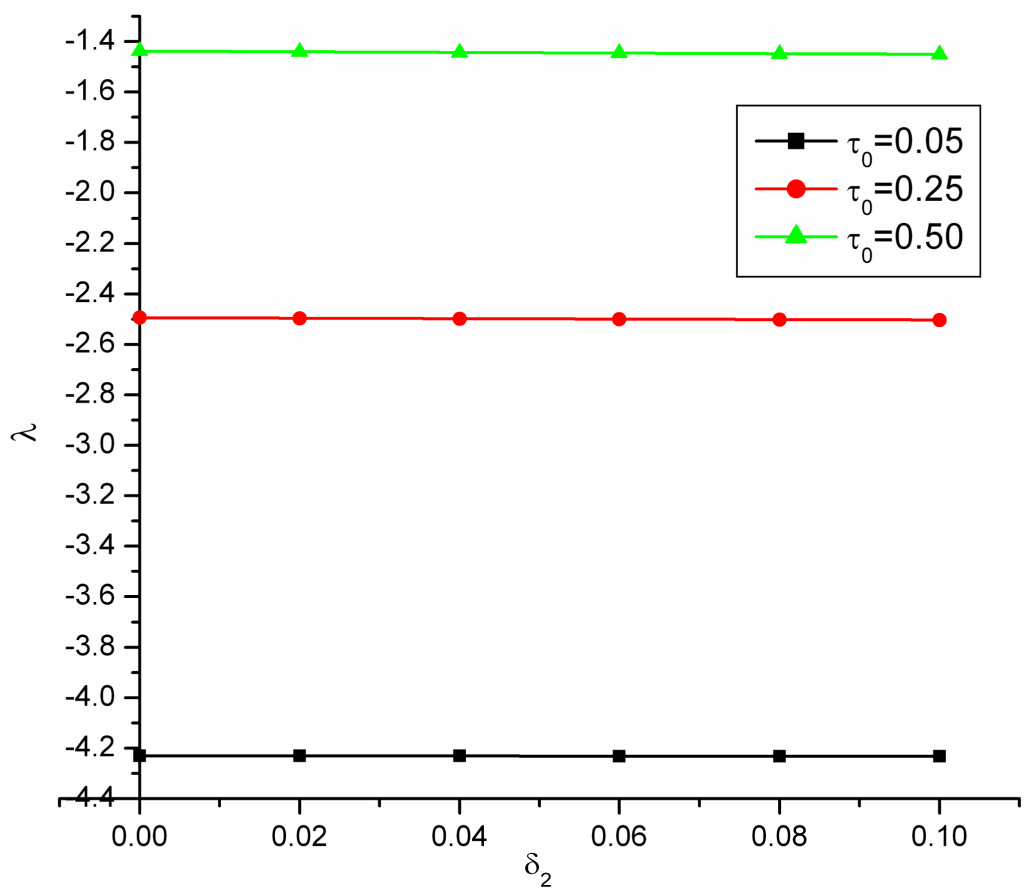

Figure 12. Variation in impedance with thickness of dilatation at $k=4, n=1.5$, $\alpha=\pi / 6, \delta_{1}=20 \%$ of $R$.

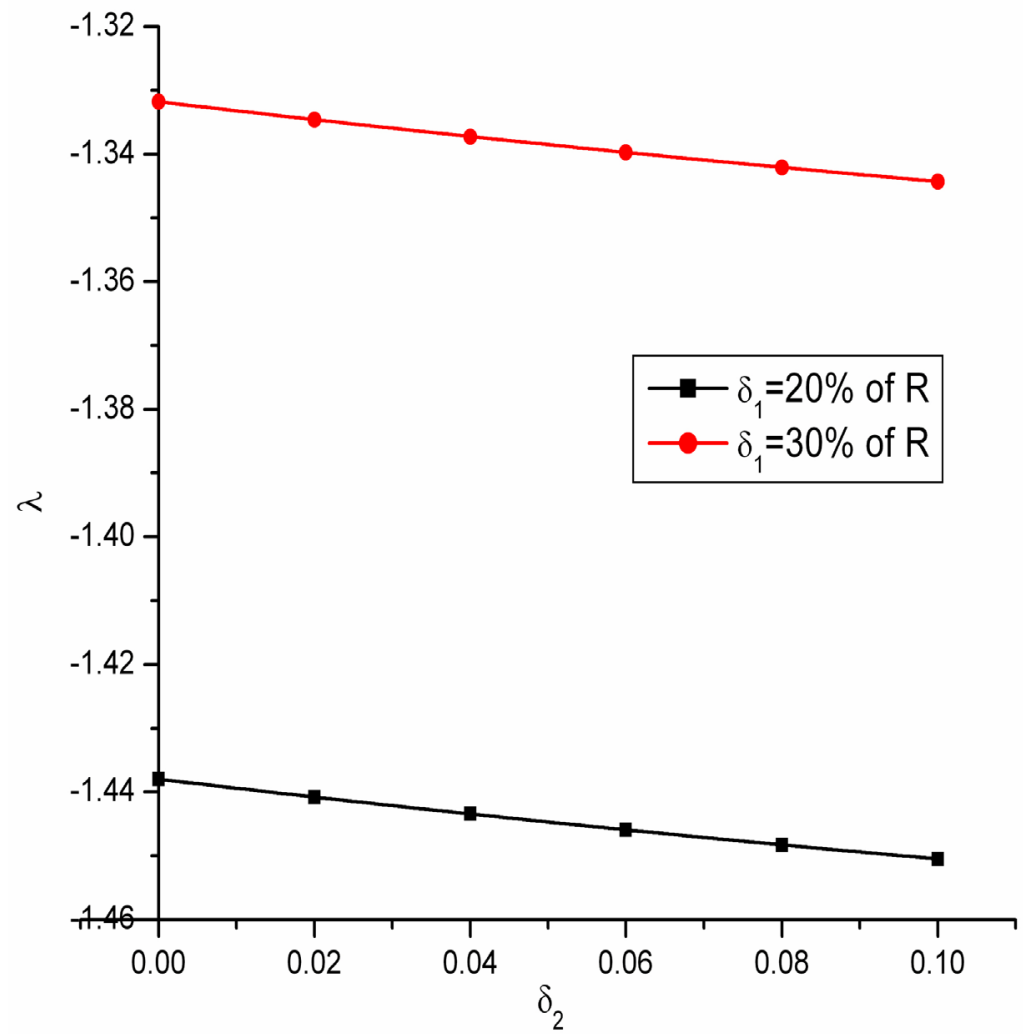

Figure 13. Variation in impedance with thickness of dilatation at $k=4, n=1.5$, $\alpha=\pi / 6, \tau_{0}=0.5$. 


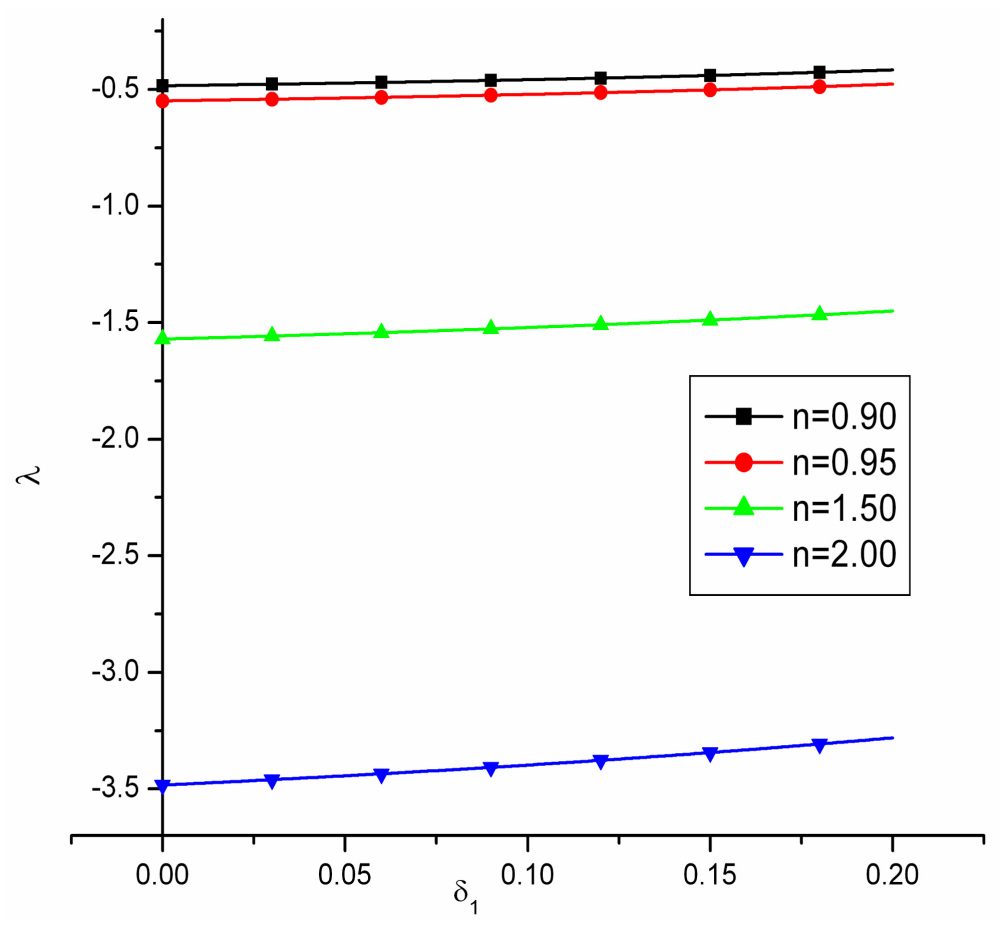

Figure 14. Variation in impedance with thickness of stenosis at $k=4, \alpha=\pi / 6$, $\tau_{0}=0.5, \delta_{2}=10 \%$ of $R$.

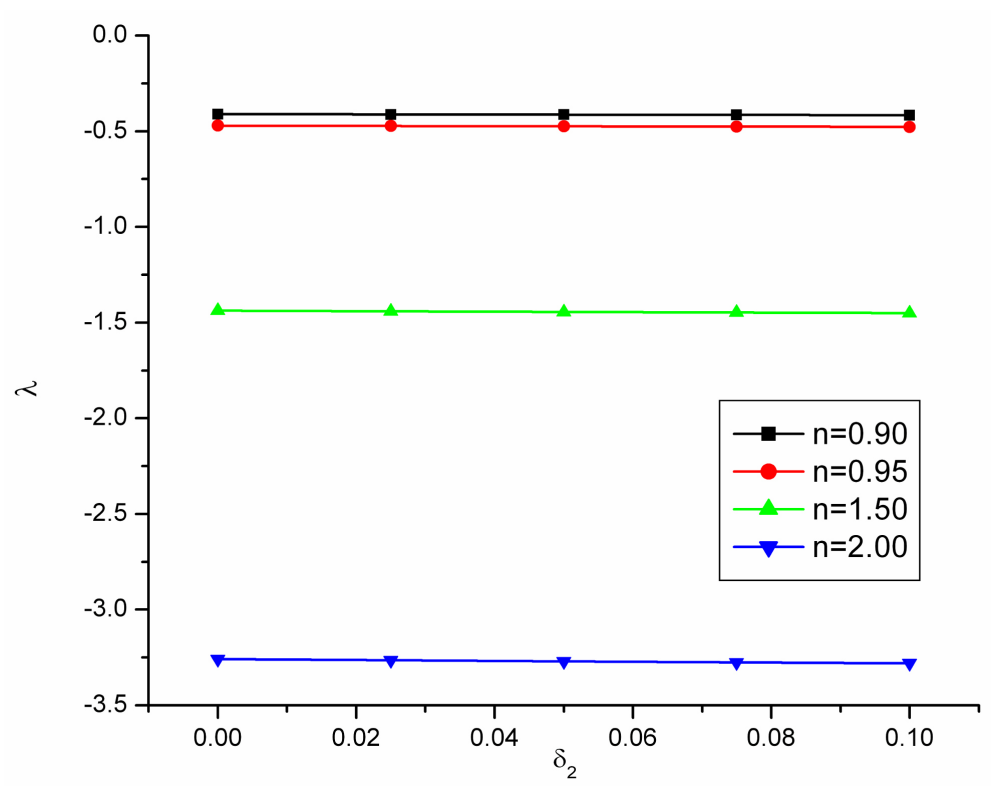

Figure 15. Variation in impedance with thickness of dilatation at $k=4, \alpha=$ $\pi / 6, \delta_{1}=20 \%$ of $R$.

reduces with the increase of $n$ since the pressure drop increases with the increasing value of $n$. Also, the impedance enhances on the advancement of thickness of stenotic region while it reduces with the increase in maximum expansion of the dilatation as observed in Figure 14 \& Figure 15 respectively. 
The inclination $\alpha$ of the vessel affects significantly on the impedance to the flow, Figure 16 \& Figure 17. The impedance to flow is increases with the increase in the

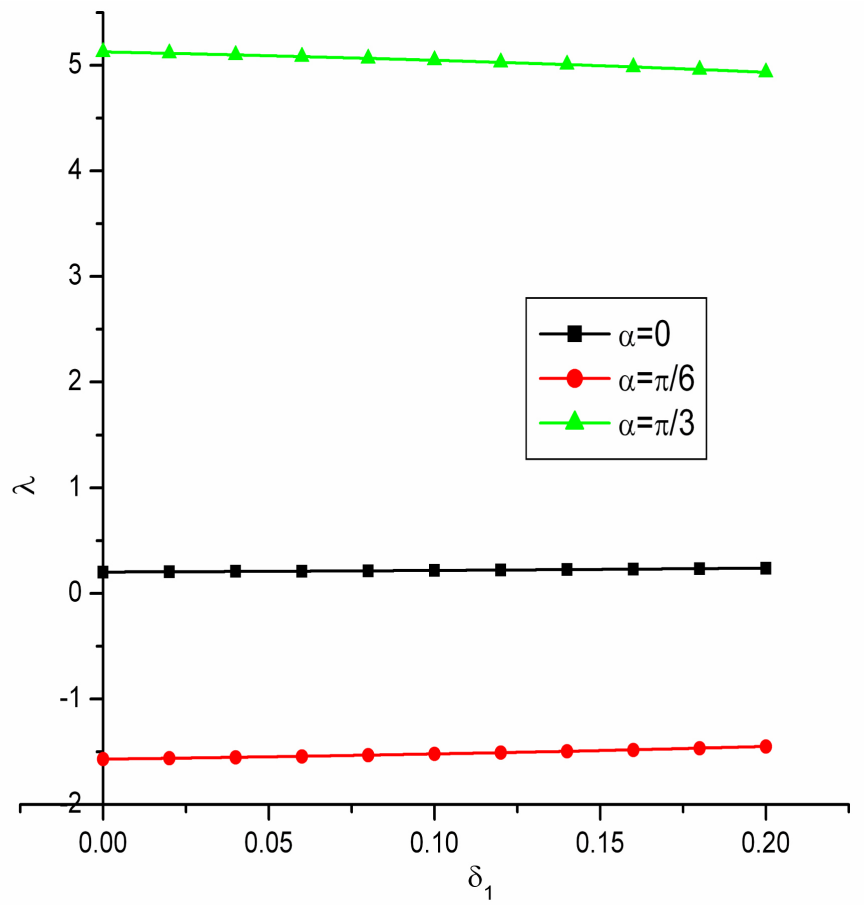

Figure 16. Variation in impedance with thickness of stenosis at $k=$ $4, n=1.5, \tau_{0}=0.5, \delta_{2}=10 \%$ of $R$.

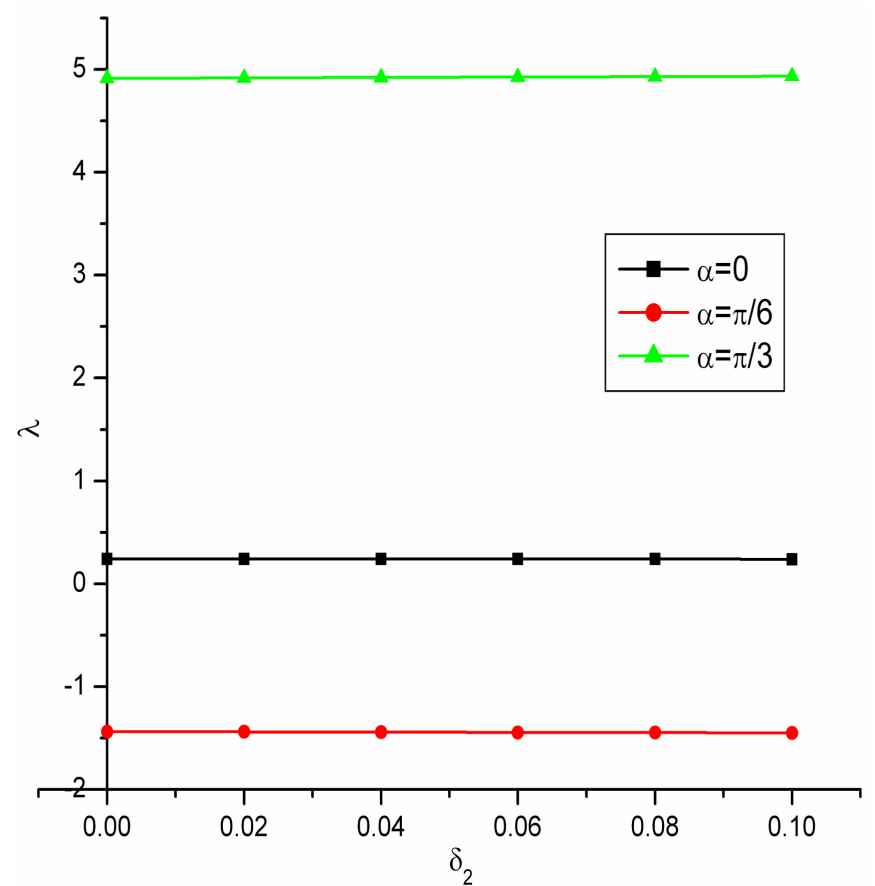

Figure 17. Variation in impedance with thickness of dilatation at $k=$ $4, n=1.5, \tau_{0}=0.5, \delta_{1}=20 \%$ of $R$. 
value of $\alpha$. At $\alpha=0$ the vessel is horizontal then the effect of gravitational field is uniform throughout. The case when $\alpha=\pi / 6$ and $\alpha=\pi / 3$ the body force term $f=\frac{\sin \alpha}{F}$ play role to retard the flow.

\section{Conclusions}

- In the dilatation region, the flow velocity reduces significantly in magnitude as compared to overlapped stenotic region or normal region of the vessel.

- The effect of non-Newtonian behaviour on the flow profiles is plausible. The profiles are not of parabolic shape.

- The increase in yield stress is due to unhealthy condition. The plug flow radius increases irrespective of the locations whether it falls within stenotic region or in the region of dilatation. On increasing power law index, the fluid gets impetus even in the plug flow region.

- Near the extremities of the overlapped stenosis, the steepest enhancement in the skin-friction is observed.

- With the increase in power law index, profound reduction in skin-friction is obtained. This suggests the importance of power law index of the blood during the theoretical studies.

- In case of unhealthy situation, the yield stress increases from its normal value. Hence with the increase in yield stress, the resistance to flow ratio increases that results in reduction in the transportation of blood, oxygen and nutrients supply to the tissues.

- The inclination $\alpha$ of the vessel affects significantly on the impedance to the flow.

- The impedance to the flow reduces with the increase of power law index.

\section{References}

[1] Sochi, T. (2010) Non-Newtonian Flow in Porous Media. Polymer, 51, 5007-5023. https://doi.org/10.1016/j.polymer.2010.07.047

[2] Shukla, J.B., Parihar, R.S. and Rao, B. (1980) Effects of Stenosis on Non-Newtonian Flow of the Blood in an Artery. Bulletin of Mathematical Biology, 42, 283-294. https://doi.org/10.1007/BF02460787

[3] Fisher, C. and Rossmann, R. (2009) Effect of Non-Newtonian Behavior on Hemodynamics of Cerebral Aneurysms. Journal of Biomechanical Engineering, 131, Article ID: 091004. https://doi.org/10.1115/1.3148470

[4] Revellin, R., Rousset, F., Baud, D. and Bonjour, J. (2009) Extension of Murray's Law Using a Non-Newtonian Model of Blood Flow. Theoretical Biology and Medical Modelling, 6, 7. https://doi.org/10.1186/1742-4682-6-7

[5] Barnes, H.A. (1997) Thixotropy-A Review. Journal of Non-Newtonian Fluid Mechanics, 70, 1-33. https://doi.org/10.1016/S0377-0257(97)00004-9

[6] Bodnar, T., Sequeira, A. and Prosi, M. (2011) On the Shear-Thinning and Viscoelastic Effects of Blood Flow under Various Flow Rates. Applied Mathematics and Computation, 217, 5055-5067. https://doi.org/10.1016/j.amc.2010.07.054

[7] Lou, Z. and Yang, W.J. (1993) A Computer Simulation of the Non-Newtonian Blood Flow 
at the Aortic Bifurcation. Journal of Biomechanics, 26, 37-49.

https://doi.org/10.1016/0021-9290(93)90611-H

[8] Ku, D.N., Giddens, D.P., Zarins, C.K. and Glagov, S. (1985) Pulsatile flow and Atherosclerosis in the Human Carotid Bifurcation. Positive Correlation between Plaque Location and Low and Oscillating Shear Stress. Arteriosclerosis, 5, 293-302.

https://doi.org/10.1161/01.ATV.5.3.293

[9] Glagov, S., Zarins, C.K., Giddens, D.G. and Ku, D. (1988) Hemodynamics and Atherosclerosis, Insights and Perspectives Gained from Studies of Human Arteries. Archives of Pathology \& Laboratory Medicine, 112, 1018-1031.

[10] Pedersen, E., Sung, H., Burlson, A. and Yoganathan, A. (1993) Two-Dimensional Velocity Measurements in a Pulsatile Flow Model of the Normal Abdominal Aortic Simulating Different Hemodynamic Conditions. Journal of Biomechanics, 26, 1237-1247. https://doi.org/10.1016/0021-9290(93)90071-L

[11] Hademenos, G.J. (1995) The Physics of Cerebral Aneurysms. Physics Today, 48, 24-30. https://doi.org/10.1063/1.881442

[12] Fox, J.L. and Hugh, A. (1996) Location of Atheroma: A Theory Based on Boundary Layer Separation. British Heart Journal, 28, 388-399. https://doi.org/10.1136/hrt.28.3.388

[13] Malek, A.M., Alper, S.L. and Izumo, S. (1999) Hemodynamic Shear Stress and Its Role in Atherosclerosis. JAMA, 282, 2035-2042. https://doi.org/10.1001/jama.282.21.2035

[14] Soliman, E. (2001) Cerebral Aneurysm. eMed. J., 2.

[15] Chakravarty, S. and Mandal, P.K. (1996) A Nonlinear Two-Dimensional Model of Blood Flow in an Overlapping Arterial Stenosis Subjected to Body Acceleration. Mathematical and Computer Modelling, 24, 43-58. https://doi.org/10.1016/0895-7177(96)00079-9

[16] Srivastava, V.P. (2002) Particulate Suspension Blood Flow through Stenotic Arteries: Effects of Hematocrit and Stenosis Shape. Indian Journal of Pure and Applied Mathematics, 33, 1353-1360.

[17] Prasad, K.M. and Radhakrishnamacharya, G. (2008) Flow of Herschel-Bulkley Fluid through an Inclined Tube of Non-Uniform Cross-Section with Multiple Stenoses. Archives of Mechanics, 60, 161-172.

[18] Srivastava, V.P., Rastogi, R. and Vishnoi, R. (2010) A Two-Layered Suspension Blood Flow through an Overlapping Stenosis. Computers and Mathematics with Applications, 60, 432441. https://doi.org/10.1016/j.camwa.2010.04.038

[19] Chakraborty, U.S., Biswas, D. and Paul, M. (2011) Suspension Model Blood Flow through an Inclined Tube with an Axially Non-Symmetrical Stenosis. Korea-Australia Rheology Journal, 23, 25-32. https://doi.org/10.1007/s13367-011-0004-8

[20] Sharma, M.K., Bansal, K. and Bansal, S. (2012) Pulsatile Unsteady Flow of Blood through Porous Medium in a Stenotic Artery under the Influence of Transverse Magnetic Field. Korea-Australia Rheology Journal, 24, 181-189. https://doi.org/10.1007/s13367-012-0022-1

[21] Wu, J., Liu, G., Huang, W., Ghista, D.N. and Wong, K.L. (2015) Transient Blood Flow in Elastic Coronary Arteries with Varying Degrees of Stenosis and Dilatations: CFD Modelling and Parametric Study. Computer Methods in Biomechanics and Biomedical Engineering, 18, 1835-1845. https://doi.org/10.1080/10255842.2014.976812

[22] Nadeem, S. and Ijaz, S. (2015) Theoretical Analysis of Metallic Nanoparticles on Blood Flow through Tapered Elastic Artery with Overlapping Stenosis. IEEE Transactions on Nanobioscience, 14, 417-428. https://doi.org/10.1109/TNB.2015.2389253

[23] Oka, S. (1981) Cardiovascular Hemorheology. Cambridge University Press, Cambridge.

[24] Moore, K.L. (1990) Clinically Oriented Anatomy. Williams and Wilkins, Baltimore. 
[25] Chaturani, P. and Ponnalagarsamy, R. (1985) A Study of Non-Newtonian Aspects of Blood Flow through Stenosed Arteries and Its Applications in Arterial Diseases. Biorheology, 22, 521-531.

[26] Radtke, H., Schneider, R., Witt, R., Kiesewetter, H. and SchmidSchönbein, H. (1984) A Measuring Device to Determine a Universal Parameter for the Flow Characteristics of Blood: Measurement of the Yield Shear Stress in a Branched Capillary. Advances in EXperimental Medicine and Biology, 169, 851-857.

https://doi.org/10.1007/978-1-4684-1188-1_79

[27] Picart, C., Carpentier, P.H., Galliard, H. and Piau, J.M. (1999) Blood Yield Stress in Systemic Sclerosis. American Journal of Physiology_Heart and Circulatory Physiology, 276, H771-H777.

[28] Lee, B., Xue, S., Nam, J., Lim H. and Shin S. (2011) Determination of the Blood Viscosity and Yield Stress with a pressure-Scanning Capillary Hemorheometer Using Constitutive Model. Korea-Australia Rheology Journal, 23, 1-6.

https://doi.org/10.1007/s13367-011-0001-y

[29] Sankar, D.S. and Hemalatha, K. (2007) A Non-Newtonian Fluid Flow Model for Blood Flow through a Catheterized Artery-Steady Flow. Applied Mathematical Modelling, 31, 1847-1864. https://doi.org/10.1016/j.apm.2006.06.009

[30] Pincombe, B. and Mazumdar, J. (1997) The Effects of Post-Stenotic Dilatations on the Flow of a Blood Analogue through Stenosed Coronary Arteries. Mathematical and Computer Modelling, 25, 57-70. https://doi.org/10.1016/S0895-7177(97)00039-3 


\section{List of Symbols}

$g \quad$ Acceleration due to gravity.

$R \quad$ Radius of unstenosed artery.

$h(z) \quad$ Radius of stenosed artery defined in the Equation (1).

$6 L$ Length of stenosed portion shown in the Figure 1.

$2 L \quad$ Length of dilatation portion shown in the Figure 1 .

$n, k \quad$ Non-Newtonian parameters taken in the Equation (11).

$\Delta p \quad$ Pressure drop.

$Q \quad$ Volumetric flow rate.

$r \quad$ Radial coordinate.

$w \quad$ Dimensionless axial velocity.

$z \quad$ Axial coordinate.

\section{Greek Letters}

$\alpha \quad$ Inclination of artery with horizontal.

$\delta_{1} \quad$ Maximum thickness of the stenosis.

$\delta_{2} \quad$ Maximum thickness of the dilatation.

$\lambda_{1} \quad$ Resistance of flow in stenosed artery.

$\lambda_{2} \quad$ Resistance of flow in normal artery.

$\lambda \quad$ Impedance.

$\mu \quad$ Viscosity.

$\rho \quad$ Density of fluid.

$\tau_{r z}^{*} \quad$ Shear stress.

$\tau_{0}^{*} \quad$ Yield stress.

Submit or recommend next manuscript to SCIRP and we will provide best service for you:

Accepting pre-submission inquiries through Email, Facebook, LinkedIn, Twitter, etc.

A wide selection of journals (inclusive of 9 subjects, more than 200 journals)

Providing 24-hour high-quality service

User-friendly online submission system

Fair and swift peer-review system

Efficient typesetting and proofreading procedure

Display of the result of downloads and visits, as well as the number of cited articles

Maximum dissemination of your research work

Submit your manuscript at: http://papersubmission.scirp.org/

Or contact jbise@scirp.org 